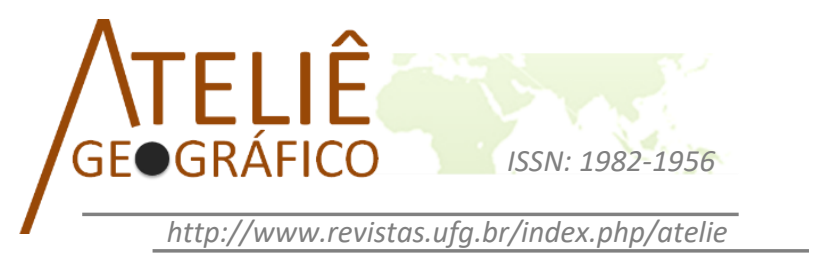

\title{
Cartografias de quem produz cartografias: narrativas dos professores sobre crianças e mapas
}

\author{
Cartographies that produces cartographies: teachers' \\ narratives about children and maps \\ Cartografías de quien produce cartografías: narrativas de \\ los profesores sobre niños y mapas
}

\author{
Daniel Luiz Poio Roberti \\ Universidade Federal Fluminense \\ daroberti@yahoo.com.br \\ Jader Janer Moreira Lopes \\ Unversidade Federal de Juiz de Fora \\ jjanergeo@gmail.com
}

\begin{abstract}
Resumo
O texto fala de mapas, crianças e escolas na visão de determinados atores. São eles: professores universitários que contribuíram para a formação da Cartografia Escolar no Brasil. A Cartografia Escolar é um campo de pesquisa que surge na interface entre Educação e Geografia, a partir das primeiras discussões empreendidas pelo grupo Geografia e Cartografia Escolar no final da década de 90. Este grupo de pesquisa é coordenado pelas professoras Rosângela Doin de Almeida e Regina Araújo Almeida. A história do grupo se mistura com a dos seus eventos acadêmicos, como os Colóquios de Cartografia para Criança e Escolares. Até o momento foram 7 eventos de Cartografia para escolares no Brasil. O objetivo de nossa pesquisa foi compreender os movimentos e práticas cartográficas que se encontram emaranhados nas narrativas dos entrevistados e nos anais dos colóquios, simpósios e fóruns de Cartografia para Crianças. Constatamos que o campo da Cartografia Escolar sofre influência de diferentes áreas do conhecimento, principalmente, da psicologia do desenvolvimento e da filosofia.
\end{abstract}

Palavras-chave: Cartografia Escolar, Colóquios para Criança e escolares, Mapas

\footnotetext{
Abstract

This text tells about maps, children and schools from who lived them. Professors, who were part of my interviews, contributed in some way to the formation of the Cartography for School children field in Brazil. Cartography for Children is a research
} 
field that arises at the interface between Education and Geography, from the earliest discussions done by the Geography and Cartography School group in the mid-90s of the twentieth century. This research group is coordinated by the teachers Rosângela Doin de Almeida (UNESP-Rio Claro) and Regina Araújo Almeida (USP / SP) and brings together leading researchers from the Scholar Cartography field. The history of the group is mixed with the events organized by it, as the Colloquium of Cartography for Children. So far there have been 7 Cartography events for schoolchildren in Brazil. The objective of this research was to understand the movements and cartographic practices that tangles are found in the narratives of my interviewees and in the Proceedings of seminars, symposium and Cartography forums for Children. We found that the field of Cartography for Children suffers influences from various areas of knowledge, especially the development of philosophy and psychology.

Keywords: Cartography for Scholar Children, Colloquium Cartography for Children, Maps

\section{Resumen}

El texto habla de mapas, los niños y las escuelas, en vista de ciertos actores. Ellos son: los profesores universitarios que han contribuido a la formación de la Cartografía escolar en Brasil. La cartografía escolar es un campo de búsqueda que aparece en la interfaz entre la educación y la geografía, desde las primeras discusiones llevadas a cabo por el grupo de la geografía escolar y Cartografía a finales de la década de los 90 . Este grupo de investigación está coordinada por los profesores Rosângela Doin de Almeida y Regina Araújo Almeida. La historia del grupo se mezcla con sus eventos académicos, como el mapeo coloquios para Niños y la Escuela. Hasta ahora, había 7 Cartografía de eventos para la escuela en Brasil. El objetivo de nuestra investigación era comprender los movimientos y las prácticas cartográficas que los ovillos se encuentran en las narrativas de los encuestados y en los anales de conferencias, simposios y foros Cartografía de la Infancia. Observamos que el campo de la Cartografía escolar está influenciada por diferentes áreas del conocimiento, sobre todo de la psicología del desarrollo y de la filosofía.

Palabras clave: Cartografia escolar, Coloquios de la Infancia y la escuela, Mapas

\section{Introdução}

Este trabalho fala acerca de mapas, crianças e escolas na visão de determinados atores. São eles: professores universitários que contribuíram para a introdução do campo de pesquisa da Cartografia Escolar. O nome Cartografia para crianças e escolares foi o escolhido para representar toda uma produção de encontros, seminários e congressos que envolviam os estudiosos de Cartografia Escolar no Brasil. A investigação aqui presente é resultado de uma pesquisa que tinha, pois, o principal objetivo de compreender os movimentos e práticas cartográficas que se encontravam emaranhados nas narrativas dos entrevistados e nos anais dos eventos de Cartografia para crianças e escolares.

Fizemos uso da análise documental e de entrevistas com o intuito de compreender quais são os principais movimentos e atores da história da cartografia e qual seria a relação epistemológica entre a cartografia e os outros campos de conhecimento. Com esse trabalho 
de investigação, buscamos interpretar, ouvir as pessoas e dialogar com as fontes documentais sobre a questão da Cartografia Escolar. Por isso, essa pesquisa se assentou num viés que historicamente vem sendo reconhecido como pesquisa qualitativa. Esta pesquisa girou em torno do caráter semiótico que formam os sujeitos, pois "O que ela (a pesquisa qualitativa) interpreta é o fluxo do discurso social e a interpretação envolvida consiste em tentar salvar o dito num tal discurso da sua possibilidade de extinguir-se e fixá-lo em formas pesquisáveis" (GEERTZ, 2008, p.31).

A nossa metodologia de pesquisa nos levou a entrevistar professores que contribuíram de alguma forma para o desenvolvimento da Cartografia Escolar no Brasil. Descobrimos esses personagens de uma história real, através dos registros dos principais eventos e produções didáticas e paradidáticas de referência da área.

\section{Metodologia}

O plano de desenvolvimento da pesquisa que aqui apresentamos foi dividido em dois momentos. No primeiro nível da investigação, utilizamos a pesquisa descritiva com o uso da análise documental de anais, boletins e revistas de publicação da AGB (Associação de Geógrafos Brasileiros), bem como os anais dos colóquios de Cartografia para Escolares. O procedimento de busca dos documentos representou

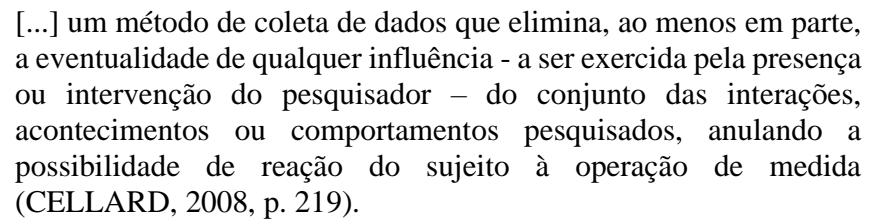

Os procedimentos de pesquisa dos materiais analisados se pautaram na análise das categorias: mapa como recurso pedagógico, ensino e cartografia inseridos no segmento básico escolar. O processo de pesquisa documental foi de suma importância para o desenvolvimento da investigação, pois pudemos explorar a nossa opção de tema e definir os conceitos que foram utilizados ao longo do nosso trabalho.

A pesquisa ao acervo documental da AGB (1978, 1980, 1986, 1988, 1990) demonstrou que os mapas só vão figurar nos anais, boletins e revistas em meados da década de 70 do século passado. A esta época, eles vão aparecer apenas como uma imagem ilustrativa, contendo alguns elementos da linguagem cartográfica. Já na década de 80, o mapa apresentará duas novas funções: a primeira como recurso de análise do espaço, já contendo elementos como projeção, escala e legenda e, a segunda, como recurso de ensino da informação espacial. A partir deste ponto, ocorre o surgimento de uma cartografia voltada para o ensino básico: ora a cartografia aparece ligada ao eixo temático do ensino, ora dispersa ao longo dos outros eixos temáticos como cidade e campo. Só a partir da década de 90 e nos anos 2000 que a AGB criará um eixo temático intitulado cartografia e 
ensino que valorizará o estado da arte de produções acadêmicas sobre a Cartografia Escolar.

Escolhemos pesquisar os anais dos eventos organizados pela AGB, pois desde os anos 30 do século passado, a Associação de Geógrafos Brasileiros promove os principais eventos nacionais de Geografia no Brasil. O ensino de cartografia aparece como eixo temático nesses espaços de produção do conhecimento geográfico. Os eventos institucionais da AGB tem um papel de destaque na história narrada e escrita do ensino de Cartografia no Brasil. Ao mesmo tempo em que a principal entidade de Geógrafos brasileiros promoveu/promove o debate em torno desse tema, contraditoriamente, nos últimos 20 anos, a AGB viu a sua hegemonia acadêmica sobre o tema se esvaecer pela organização autônoma de uma rede de pesquisadores das áreas de Cartografia, metodologia e práticas escolares.

Dentre o corpus selecionado para nossa a análise, destacamos os anais dos Colóquios de Cartografia paraescolares, documentos a figurar nestes eventos que reúnem os principais pesquisadores do campo da Cartografia Escolar. O primeiro destes encontros surgiu no ano de 1995 e foi realizado no campus de Rio Claro da Unesp, a partir do desejo das professoras Rosângela Doin de Almeida (UNESP-Rio Claro) e Regina Araújo de Almeida (USP) de conhecerem os pesquisadores que desenvolviam trabalhos no Brasil sobre Cartografia Escolar.

O Colóquio foi organizado com o objetivo de reunir professores e outros especialistas brasileiros envolvidos com o tema Cartografia e Crianças, visando uma apresentação de suas pesquisas e experiências práticas com a produção e o uso de mapas voltados ao público infanto-juvenil (Colóquio Cartografia para Crianças, 1995).

Ao analisarmos produção científica dos professores-pesquisadores que mais coordenaram mesas e realizaram palestras nos eventos de Cartografia para escolares, percebemos que os temas mais comuns de pesquisa entre eles eram os estudos da psicogenética do espaço.

No segundo nível de análise, optamos pela investigação qualitativa, porque almejávamos compreender a complexidade do pensamento dos professores que são referência no ensino de cartografia. Entrevistamos professores que deixaram um importante legado científico para a constituição do campo da Cartografia Escolar brasileiro. O objetivo destas entrevistas foi entender o que está por trás dos discursos destes docentes, ou seja, quais são as correntes pedagógicas e as teorias educativas que corroboram com as suas práticas escolares. Segundo Albarello et al. (1995, p.85), a pesquisa qualitativa evoca um paradoxo que "[...] consiste interrogar um ser singular quando as ciências sociais se interessam pelo coletivo. O indivíduo é interrogado quando representante de um grupo social". 
Nós ainda escolhemos as entrevistas semiestruturadas, porque acreditamos que esta técnica permite que

o próprio entrevistado estruture o seu pensamento em torno do objeto perspectivado, e daí o aspecto parcialmente não diretivo. Por outro lado, porém a definição do objeto de estudo elimina do campo de interesse diversas considerações para as quais o entrevistado se deixa naturalmente arrastar, ao sabor do seu pensamento, e exige o aprofundamento de pontos que ele próprio não teria explicitado, e daí, desta vez, o aspecto parcialmente diretivo das intervenções do entrevistador (ALBARELLO, et al., 1995, p.87).

Participaram das entrevistas dez professores de universidades públicas brasileiras e norte-americanas cujas produções acadêmicas contribuíram para a formação e consolidação do movimento da Cartografia Escolar no Brasil. As pesquisas de campo demonstraram que esse grupo apresenta algumas semelhanças na formação acadêmica.

Há uma primeira geração de professores de geografia, todos da USP, que são considerados introdutores dos estudos psicogenéticos sobre representação do espaço no Brasil (ALMEIDA, 2011). Estes docentes foram fortemente influenciados pelas pesquisas sobre espaço geométrico que foram realizadas pelo Laboratório de Genebra (Suiça). Há também uma segunda geração de pesquisadores, que até certa medida foi formada pela primeira. Atualmente, os professores da segunda geração se encontram lotados em departamentos e credenciados a programas de pós-graduação em educação. Estes pesquisadores têm realizado estudos nos campos epistemológicos da filosofia e da psicologia.

\section{Resultados e Discussão}

O enfoque metodológico do trabalho de pesquisa se preocupou em estudar as pessoas na/da cultura. Nesta relação, o humano não pode ser tomado como refém da mesma e nem esta pode ser considerada objeto do mesmo. Concordamos com a professora Marisol (Entrevista 1, 2015), quando ela discute a relação histórico-dialética entre as pessoas e a cultura: "somos humanos por causa da nossa ação no mundo que transforma $o$ mundo e o homem".

Seres humanos e mundo formam uma unidade. Unidade, segundo a acepção conceitual de Vigotski $(2012$, p. 24), "[...] un todo único, pero una unidad estrutural homogênea y simples, sino diversa e compleja". Esta unidade é, ao mesmo tempo, homogênea e complexa, porque o homem não consegue lidar com o contexto cultural tal qual ele é; para enfrentá-lo, o homem cria instrumentos.

O mesmo movimento histórico que faz com que o homem crie instrumentos, a partir da cultura, impulsiona-o a atuar na cultura; por isso ele é um ser na/da cultura. 
Segundo Marx (2004, p.34), “(...) ao atuar, por meio desse movimento, sobre a natureza externa ao homem e ao modificá-lo, ele modifica, ao mesmo tempo, sua própria natureza”.

O mapa é um exemplo de instrumento, porque ele, simultaneamente, é da cultura e se realiza nela. Se a nossa pesquisa caminhasse apenas para o estudo da gênese do mapa na cultura, permitiríamos pensar que o mapa foi uma ferramenta, dentre várias que o homem criou, para libertá-lo do confinamento da memória e alongar o seu conhecimento de mundo. Nessa pesquisa, assumimos o mapa como forma de registro cultural, como linguagem e a (re)significação dele é feita pela escola; principalmente, a escola brasileira.

Todas as práticas cartográficas estudadas nesta pesquisa carregam esse traço característico da ferramenta cultural, ou seja, que é lidar com o mundo e ampliar o conhecimento sobre este próprio mundo e ao transformar o mundo, busca também transformar o sujeito. Práticas que nos foram reveladas pelas entrevistas realizadas com dez professores em suas condições histórico-culturais, que participaram da constituição da Cartografia Escolar no Brasil. Eles formam um grupo de professores universitários com pesquisas relevantes nesse campo do conhecimento.

Os nossos entrevistados têm uma longa vivência na/da escola básica. Eles foram alunos no período obrigatório de escolarização, muitos se tornaram professores do ensino básico e depois, quando todos passaram a integrar o quadro docente no ensino superior; os seus temas de pesquisa apontavam em direção à escola.

Uma escola, em que alguns dos entrevistados a vivenciaram, pela primeira vez, há mais de meio século. Muita coisa mudou nela. Muita coisa mudou nas aulas de Geografia e no ensino de mapas. Essa experiência de quase 50 anos de história dentro da escola, trouxe uma série de atravessamentos que contribuíram para formá-los. A nossa pesquisa se interessou por isso, em buscar compreender a constituição da Cartografia Escolar no Brasil pelo que as fontes bibliográficas e os sujeitos permitiram nos revelar.

Práticas cartográficas que respondiam aos contextos da escola, mas que também propunham questionamentos a essa mesma escola. Alguns exemplos da relação entre ensino de mapas e contexto escolar foram alvos de discussão na pesquisa. $O$ ensino pelo mapa, como nos descreve a professora Lívia de Oliveira (2014), foi uma marca das aulas de Geografia no Brasil. Talvez, o maior símbolo deste ensino foi o representado pela figura do mapa político-administrativo (OLIVEIRA JR, 2011). O ensino pelo mapa ou através do mapa tinha o profícuo objetivo de mostrar para os alunos um mundo divido por fronteiras estáveis e harmônicas, garantidas pelo poder administrativo do estado. É um tipo de Geografia, que segundo Lacoste (1988, p. 38), valorizava o conhecimento do professor e desvalorizava o saber do aluno:

o professor sobretudo dantes, obrigava a "fazer" muitos mapas (...) são imagens simbólicas que o aluno deve desenhar por si próprio: dantes era mesmo proibido decalcar, talvez para melhor o apreender. A imagem mágica que deve ser reproduzida pelo aluno é, antes de 
mais nada, a Pátria. Outros mapas representavam outros Estados, entidades políticas cujo esquematismo dos caracteres simbólicos vem reforçar ainda mais a ideia de que a nação onde vivemos é um dado intangível (dado por quem?), apresentado como se tratasse não de uma construção histórica, mas de um conjunto espacial engendrado pela natureza. É sintomático que o termo eminentemente geográfico "país" tenha suplantado, em todas as matérias, as noções políticas de Estado, de nação...

As práticas cartográficas no Brasil acompanharam a Geografia dos professores (LACOSTE, 1988), através de atividades que exigiam dos alunos a cópia de mapas ou o preenchimento de mapas-mudos. A localização e posterior descrição do fenômeno geográfico eram habilidades desenvolvidas pela aula de Geografia. O mapa se situou como uma ferramenta auxiliar no ensino dessa disciplina.

A infância escolarizada dos nossos entrevistados vivenciou poucas práticas cartográficas que fugissem a este tipo de modelo de Geografia mais tradicional, ou seja, uma disciplina preocupada com nomes de lugares, nomenclaturas e limites administrativos do estado (ROCHA, 2009).

A renovação na educação cartográfica brasileira só veio a ocorrer em meados da década de 90, a partir de pesquisas e colóquios que ajudaram a formar um campo próprio de investigação.

Geografia e Cartografia Escolar foi o primeiro grupo de pesquisa a colocar o ensino de Cartografia para crianças como pauta de debate nos movimentos da Geografia escolar. Ele foi fundado no ano de 1995, pelas professoras Rosângela Doin de Almeida (UNESP-Rio Claro) e Regina Araújo de Almeida (USP) com o intuito de poder participar da Comissão Cartografia e Crianças (CCC) da Associação Internacional de Cartografia (ICA). No Brasil, a ideia de formação do grupo de pesquisa foi para sistematizar os debates em torno da Cartografia Escolar no Brasil. Gisele Girardi questiona qual foi a principal intenção de formação do grupo: "Não tem problema, isso faz parte da origem, mas eu acho que ele tem muito esse caráter, menos de uma discussão interna ou de uma necessidade de um grupo de pesquisa e mais essa resposta institucional mais forte" (Entrevista 3, 2015).

Os colóquios e os eventos organizados pelo grupo de pesquisa da Cartografia Escolar se transformaram em relevantes movimentos acadêmicos, que reuniam pesquisadores do Brasil inteiro, em torno do mesmo campo.

A proporção institucional que os colóquios de Cartografia Escolar conseguiram, foi algo antes inimaginável/incontrolável pelos integrantes do grupo formador. No primeiro Colóquio de Cartografia para Crianças em 1995 foram 14 instituições de ensino diferentes, 22 participantes e 17 trabalhos inscritos. No quinto evento organizado pelo grupo de pesquisa, o I Simpósio Ibero-americano de Cartografia para Crianças, foram 52 instituições de ensino e fomento, 246 participantes e 106 trabalhos apresentados. Crescimento vertiginoso do evento em pouco mais de 7 anos de existência (MELO, 2007). 
Sobre esse crescimento no número de pessoas interessadas na/pela Cartografia Escolar, a professora Valéria Trevizani comenta que "[...] você tem aí uma segunda, terceira e até quarta geração já; de que estão preocupadas e refletindo sobre o ensino de Cartografia" (Entrevista 3, 2015).

A nossa pesquisa se interessou mais pelos encaminhamentos teóricometodológicos proporcionados pelos colóquios de Cartografia Escolar. Encaminhamentos teórico-metodológicos que puderam ser entendidos pelas pesquisas relacionadas à área de métodos e teorias de ensino, que abordam os processos de aprendizagens dos alunos. Então, a renovação no movimento de ensino de Cartografia, pela história das pesquisas no campo e dos colóquios, pode ser divididas em duas partes: Um primeiro momento, com mudanças diretas introduzidas pelo grupo de pesquisa que impactaram o movimento do ensino de Cartografia na escola e um segundo momento, proporcionado por mudanças indiretas do grupo de pesquisa na Cartografia Escolar.

Todas as transformações provocadas pelo grupo de pesquisa na educação cartográfica só puderam se realizar, porque o contexto educacional brasileiro se tornou favorável à transferência de novas teorias pedagógicas. Foi o momento de intensas discussões na academia brasileira sobre a relevância do instrumental teórico-metodológico do construtivismo para a educação. Com o construtivismo pedagógico há uma espécie de valorização dos processos de produção do conhecimento em detrimento ao contexto de sua reprodução do real; do aluno como sujeito ativo na produção do próprio saber e do professor no processo de colaboração para promover uma situação social do desenvolvimento escolar.

As inovações diretas provocadas pelo grupo de pesquisa na educação cartográfica brasileira começaram com a mudança paradigmática do processo-conceito de ensino de Cartografia, amplamente dependente do campo epistemológico da Geografia Escolar; para a criação de um campo próprio do conhecimento sobre representação do espaço na escola: a Cartografia Escolar.

A psicologia do desenvolvimento influenciou muito os movimentos de renovação da Cartografia Escolar no Brasil. O grupo de pesquisa promoveu os primeiros debates no universo acadêmico-escolar sobre a psicogenética do espaço, baseando-se nas obras de referência de Jean Piaget sobre o espaço geométrico. Muitos geógrafos fizeram a correlação metodológica entre o pensamento piagetiano sobre espaço e o construtivismo pedagógico; pois, os dois trabalham com a aprendizagem a partir da ação do sujeito aprendente em direção ao objeto do conhecimento.

Os professores que seguem o pensamento piagetiano na Cartografia Escolar defendem que primeiro o sujeito precisa passar/conhecer pelo/o espaço para depois entendê-lo. $\mathrm{O}$ aluno precisa se apropriar de todas as partes, que formam o espaço, para melhor compreendê-lo em sua totalidade. O espaço é visto como a soma de seus pedaços. A relação que o sujeito tem com o espaço depende principalmente do seu estágio de desenvolvimento cognitivo. Conforme, a criança amadurece biologicamente, ela se adapta 
ao espaço produzido pelos homens. Em relação à representação cartográfica, há uma valorização do grafismo infantil, enquanto etapa necessária para as crianças aprenderem os mapas dos adultos.

As crianças precisam enfrentar os mesmos desafios impostos aos homens na história do desenvolvimento da humanidade para deixar graficamente registrado a localização de seus espaços. As habilidades requisitadas para tal tarefa são copiar, selecionar, comparar, sintetizar a informação gráfica no mapa. Sobre a relação entre o desenvolvimento da humanidade e da criança, Valéria Trevizani entende que

\begin{abstract}
a história do individuo, ela nesse aspecto, ela é muito similar a da humanidade. Você vê quantos anos, quantos séculos se demorou para chegar a conclusão que o sistema solar prevalecia, o Sol, centro do universo, quanto a criança demora para sair dessa problemática, é uma revolução que ela é o centro do mundo, depois ela não é mais. (Entrevista 3, 2015).
\end{abstract}

Até o quinto Colóquio de Cartografia para Crianças, a perspectiva piagetiana era tida como a concepção teórico-metodológica predominante da Cartografia Escolar. A partir do sexto Colóquio de Cartografia para Crianças na UFJF/Juiz de Fora, no ano de 2009, a perspectiva piagetiana de leitura do espaço começou a sofrer críticas de movimentos tanto de dentro, como de fora da Cartografia Escolar. Mesma época em que o construtivismo interacionista no campo da educação passava por um período de reconstrução das suas bases fundantes. As críticas, sobre a separação por etapas do desenvolvimento humano, atravessavam todo o pensamento piagetiano na educação.

O próprio nome do movimento, construtivismo interacionista e a concepção teórico-metodológica que ele carrega foram duramente criticados na educação por polarizar o sujeito e o conhecimento. O mundo era tomado como um objeto cognoscível localizado fora do sujeito.

Novas abordagens teórico-metodológicas foram assumidas por alguns intelectuais do campo do ensino. Os exemplos são variados e vão desde o campo da filosofia com a Fenomenologia e a Filosofia da diferença até o campo da psicologia do desenvolvimento com a Teoria Histórico-Cultural. A Filosofia da diferença e a Teoria Histórico-Cultural são as duas matrizes de pensamento que surgem nas falas dos professores entrevistados, quando eles discutem a renovação da Cartografia Escolar. As duas correntes concordam que a humanidade se desenvolveu através de saltos geracionais qualitativos na cultura não havendo a necessidade que o individuo refaça o caminho do desenvolvimento na história. A ferramenta e a memória expressam esse desenvolvimento do sujeito histórico na/da cultura.

Michael Tomasello, um autor que segue a perspectiva da Teoria HistóricoCultural, nos ajudou a refletir sobre a relevância da ferramenta para o desenvolvimento 
humano. Ele discute a capacidade ontológica do sujeito de fazer parte e apropriar-se da ferramenta cultural.

\begin{abstract}
Algumas tradições culturais acumulam as modificações feitas por diferentes indivíduos no transcurso do tempo de modo tal que elas se tornam mais complexas, abrangendo um espectro mais amplo de funções adaptativas - o que pode ser chamado de evolução cultural cumulativa ou de efeito catraca (TOMASELLO, 2003, p.50).
\end{abstract}

No sétimo Colóquio de Cartografia, que aconteceu no ano de 2011 na UFES/Vitória, ficou mais claro o tensionamento entre os grupos e suas diferentes escolhas teóricas, seus fundamentos e diálogos com diferentes autores e as aproximações com a Cartografia Escolar.

Deleuzianos e vigotskianos concordam que a Cartografia deva ser um meio de produção do conhecimento espacial pelos principais usuários dela: as crianças. A Cartografia Educativa não tem como fim a aprendizagem do mapa do adulto, o mapa é mais uma possibilidade de expressão gráfica do mundo pelo sujeito. $\mathrm{O}$ professor Wenceslao busca dialogar com esse pensamento cartográfico quando diz que o mapa é "[...] praticamente tudo" (Entrevista 2, 2015). Esse tudo da fala de Wenceslao tem o sentido de expressar o mundo do/no sujeito num determinado contexto histórico-espacial.

\title{
Conclusão
}

Nos últimos 30 anos, os professores-pioneiros da Cartografia Escolar contribuíram para a formação de um campo de pesquisa autônomo em relação à Geografia escolar. É um campo que apresenta um conjunto de métodos e teorias consolidados por pesquisas empíricas que atendem desde o processo de ensino-aprendizagem dos alunos da escolarização básica até a formação de professores para atuarem na área.

A trajetória histórica da Cartografia Educativa é menos pavimentada que a da sua coirmã; a Escolar. São poucas pesquisas empíricas, até o momento, que referendam as proposições epistemológicas da Cartografia Educativa. Apesar disso, defendemos que esta Cartografia se encontra num campo de produção de conhecimento vastíssimo; porque não é só dedicada ao universo escolar, dialoga com e se alimenta das práticas sociais. Acredito que o diálogo entre o movimento da Geografia da Infância (LOPES, 2005) e a Cartografia Educativa possa se tornar profícuo, principalmente numa leva atual de discussões que se fazem presente na educação infantil e na pré-escola cujas propostas se preocupam pela atividade criativa da criança no espaço que lhe é reservado pelo adulto.

Talvez, todas essas perspectivas, todas essas falas e narrativas aqui coletadas nos evidenciem a pluralidade de formas de lidar com o mapa, uma pluralidade de fazer Cartografias para crianças e escolares, a pluralidade de formas e caminhos de se fazer uma Cartografia com crianças e escolares. Talvez devêssemos falar em Cartografias em seu 
sentido plural, já que há diferentes movimentos dentro de um movimento que teve início há décadas, como essa pesquisa buscou evidenciar.

\section{Referências}

ALBARELLO, Luc; ALMEIDA, José Soares de; BAPTISTA, Luísa. Práticas e Métodos de Investigação em Ciências Sociais. Lisboa: Gradiva, 1995.

ALMEIDA, Rosângela Doin. Cartografia escolar. Editora Contexto, 2011.

ASSOCIAÇÃO DOS GEÓGRAFOS BRASILEIROS, III., 1978. Ceará. Encontro Nacional de Geógrafos/Volume XIX - Resumos. São Paulo: AGB, 1978.

ASSOCIAÇÃO DOS GEÓGRAFOS BRASILEIROS, IV, 1980. Rio de Janeiro. Encontro Nacional de Geógrafos - Resumos. Rio de Janeiro: AGB, 1980.

ASSOCIAÇÃO DOS GEÓGRAFOS BRASILEIROS, VI., 1986. Mato Grosso do Sul. Encontro Nacional de Geógrafos - Contribuições científicas. Mato Grosso do Sul: FUCMT/FUFMS, 1986. 345 p.

ASSOCIAÇÃO DOS GEÓGRAFOS BRASILEIROS, VII., 1988. Alagoas. Encontro Nacional de Geógrafos/Geografia e Realidade Brasileira: Formas de resistência Resumos. Alagoas: AGB, 1988. 301 p.

ASSOCIAÇÃO DOS GEÓGRAFOS BRASILEIROS, VIII., 1990. Bahia. Encontro Nacional de Geógrafos - Contribuições científicas/Movimento Brasileiro. Movimento Geográfico. Território, Ambiente, Cidadania. Bahia: AGB, 1990. 345 p.

ASSOCIAÇÃO DOS GEÓGRAFOS BRASILEIROS, X., 1996. Pernambuco. Encontro Nacional de Geógrafos - Contribuições científicas/Espacialidade e Territorialidade:

Limites da Simulação. Pernambuco: UFPE, 1996. 206 p.

CELLARD, André. A análise documental. In: J. E. Poupart (org.). A pesquisa qualitativa. Enfoques epistemológicos e metodológicos. Petrópolis: Vozes, 2008.

COLÓQUIO CARTOGRAFIA PARA CRIANÇAS, 1995, Rio Claro. ANAIS PROCEEDINGS. Rio Claro: Unesp, 1995.

ENTREVISTA REALIZADA EM 27/01/2014 NA CIDADE DE RIO CLARO/SP COM A PROFA. ROSÄNGELA DOIN DE ALMEIDA, BLOCO 2.

ENTREVISTA REALIZADA EM 27/01/2014 NA CIDADE DE RIO CLARO/SP COM

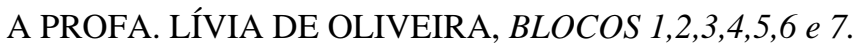

ENTREVISTA REALIZADA EM 18/08/2015 NA CIDADE DE VITÓRIA/ES COM A PROFA. GISELE GIRARDI, BLOCOS 3. 
ENTREVISTA REALIZADA EM 25/08/2015 NA CIDADE DE CAMPINAS/SP COM O PROF. WENCESLAO MACHADO DE OLIVEIRA JUNIOR, BLOCOS 2.

ENTREVISTA REALIZADA EM 19/08/2015 NA CIDADE DE NITERÓI/RJ COM A PROFA. MARISOL BARENCO DE MELO, BLOCO 1.

ENTREVISTA REALIZADA EM 27/08/2015 NA CIDADE DE JUIZ DE FORA COM A PROF. VALÉRIA TREVIZANI BURLA AGUIAR, BLOCOS 3.

GEERTZ, Clifford. A interpretação das culturas. - l.ed., IS.reimpr. - Rio de Janeiro: LTC, 2008.

LACOSTE, Yves. A Geografia-Isso Serve. Primeiro Lugar, para fazer a Guerra. Campinas, SP: Papirus, 1988.

LOPES, Jader Janer Moreira; VASCONCELLOS, Tânia de. Geografia da infância: reflexões sobre uma área de pesquisa. Juiz de Fora: FEME, p. 80, 2005.

MARX, Karl. Manuscritos econômico-filosóficos. Boitempo Editorial, 2004.

MELO, Ismail. Proposição de uma cartografia escolar no ensino superior. Programa de doutorado, área de concentração: organização do espaço, UNESP-Rio Claro, 2007.

OLIVEIRA JR, Wenceslao. A educação visual dos mapas. Revista Geográfica de América Central, p. 1-16, 2011.

ROCHA, Genilton. Por uma geografia moderna na sala de aula: Rui Barbosa e Delgado de Carvalho e a renovação do ensino de Geografia no Brasil (for a modern geography in classroom). Revista Mercator, v. 8, n. 15, p. p. 75 a 94, 2009

TOMASELLO, Michael. Origens culturais da aquisição do conhecimento humano (Berliner, C., trad.). São Paulo: Martins Fontes, 2003.

VYGOTSKI, Lev. Obras escogidas V: Fundamentos de defectologia. Madrid: Machado Nuevo Aprendizaje, 2012.

\footnotetext{
Daniel Luiz Poio Roberti

Graduado em Geografia pela Universidade Federal Fluminense, mestre em Ciências da Educação pela Universidade Lusófona de Humanidades e Tecnologias e doutor em Educação pela UFF. Atualmente é professor adjunto da Universidade Federal Fluminense (IEAR).

Universidade Federal Fluminense, IEAR, Avenida do Trabalhador, Verolme, 23914360 - Angra dos Reis, RJ - Brasil, Telefone: (24) 33651642.

E-mail: daroberti@yahoo.com.br
} 


\section{Jader Janer Moreira Lopes}

Possui graduação em Geografia pela Universidade Federal de Juiz de Fora, mestrado em Educação pela Universidade Federal de Juiz de Fora, doutorado em Educação pela Universidade Federal Fluminense e pós-doutorado pelo Internationaler Promotionsstudiengang Erziehungswissenchaft/Psychologie- INEDD, da Universität Siegen, Alemanha. Atualmente é professor do programa de pós Graduação em Educação da Universidade Federal Fluminense e da Universidade Federal de Juiz de Fora, onde orienta mestrado e doutorado.

Universidade Federal de Juiz de Fora (Campus UFJF), Faculdade de Educação, São Pedro, 36036900 - Juiz de Fora, MG - Brasil, Telefone: (32) 21023978.

E-mail: jjanergeo@gmail.com

Recebido para publicação em abril de 2017 Aprovado para publicação em agosto de 2018 